\title{
Modifiable Risk Factors for Prevention of Dementia in Midlife, Late Life and the Oldest-Old
}

Citation for published version (APA):

Vos, S. J. B., van Boxtel, M. P. J., Schiepers, O. J. G., Deckers, K., de Vugt, M., Carriere, I., Dartigues, JF., Peres, K., Artero, S., Ritchie, K., Galluzzo, L., Scafato, E., Frison, G. B., Huisman, M., Comijs, H. C., Sacuiu, S. F., Skoog, I., Irving, K., O'Donnell, C. A., ... Köhler, S. (2017). Modifiable Risk Factors for Prevention of Dementia in Midlife, Late Life and the Oldest-Old: Validation of the LIBRA Index. Journal of Alzheimer's Disease, 58(2), 537-547. https://doi.org/10.3233/JAD-161208

Document status and date:

Published: 01/01/2017

DOI:

10.3233/JAD-161208

Document Version:

Publisher's PDF, also known as Version of record

Document license:

Taverne

Please check the document version of this publication:

- A submitted manuscript is the version of the article upon submission and before peer-review. There can be important differences between the submitted version and the official published version of record.

People interested in the research are advised to contact the author for the final version of the publication, or visit the DOI to the publisher's website.

- The final author version and the galley proof are versions of the publication after peer review.

- The final published version features the final layout of the paper including the volume, issue and page numbers.

Link to publication

\footnotetext{
General rights rights.

- You may freely distribute the URL identifying the publication in the public portal. please follow below link for the End User Agreement:

www.umlib.nl/taverne-license

Take down policy

If you believe that this document breaches copyright please contact us at:

repository@maastrichtuniversity.nl

providing details and we will investigate your claim.
}

Copyright and moral rights for the publications made accessible in the public portal are retained by the authors and/or other copyright owners and it is a condition of accessing publications that users recognise and abide by the legal requirements associated with these

- Users may download and print one copy of any publication from the public portal for the purpose of private study or research.

- You may not further distribute the material or use it for any profit-making activity or commercial gain

If the publication is distributed under the terms of Article $25 \mathrm{fa}$ of the Dutch Copyright Act, indicated by the "Taverne" license above, 


\section{Modifiable Risk Factors for Prevention of Dementia in Midlife, Late Life and the Oldest-Old: Validation of the LIBRA Index}

Stephanie J.B. Vos ${ }^{\mathrm{a}, *}$, Martin P.J. van Boxtel ${ }^{\mathrm{a}}$, Olga J.G. Schiepers ${ }^{\mathrm{a}}$, Kay Deckers ${ }^{\mathrm{a}}$, Marjolein de Vugt ${ }^{\mathrm{a}}$, Isabelle Carrière ${ }^{\mathrm{b}, \mathrm{c}}$, Jean-François Dartigues ${ }^{\mathrm{d}, \mathrm{e}}$, Karine Peres ${ }^{\mathrm{d}, \mathrm{e}}$, Sylvaine Artero $^{\mathrm{b}, \mathrm{c}}$, Karen Ritchie ${ }^{\mathrm{b}, \mathrm{c}, \mathrm{f}}$, Lucia Galluzzo ${ }^{\mathrm{g}}$, Emanuele Scafato ${ }^{\mathrm{g}}$, Giovanni B. Frisoni ${ }^{\text {h,i }}$, Martijn Huisman ${ }^{\mathrm{j}, \mathrm{k}}$, Hannie C. Comijs ${ }^{1}$, Simona F. Sacuiu ${ }^{\mathrm{m}}$, Ingmar Skoog ${ }^{\mathrm{n}}$, Kate Irving ${ }^{\mathrm{o}}$, Catherine A. O’Donnellp ${ }^{\text {, Frans R.J. Verhey }}{ }^{\mathrm{a}}$, Pieter Jelle Visser ${ }^{\mathrm{a}, \mathrm{q}}$ and Sebastian Köhler ${ }^{\mathrm{a}}$ ${ }^{a}$ Department of Psychiatry and Neuropsychology, School for Mental Health and Neuroscience, Alzheimer Center Limburg, Maastricht University, Maastricht, The Netherlands

${ }^{\mathrm{b}}$ Inserm, U1061, Montpellier, France

${ }^{\mathrm{c}}$ University Montpellier, U1061, Montpellier, France

${ }^{\mathrm{d}}$ University Bordeaux, ISPED, Centre INSERM U1219 - Bordeaux Population Health Research Center, Bordeaux, France

${ }^{\mathrm{e}}$ INSERM, ISPED, Centre INSERM U1219 - Bordeaux Population Health Research Center, Bordeaux, France

${ }^{\mathrm{f}}$ Faculty of Medicine, Imperial College, London, UK

${ }^{\mathrm{g}}$ Population Health and Health Determinants Unit, National Centre for Epidemiology, Surveillance and Health Promotion, Istituto Superiore di Sanità, Rome, Italy

${ }^{\mathrm{h}}$ University Hospitals and University of Geneva, Geneva, Switzerland

i IRCCS Fatebenefratelli, Brescia, Italy

${ }^{\mathrm{j}}$ Department of Epidemiology and Biostatistics and EMGO Institute for Health and Care Research, VU University Medical Center, Amsterdam, The Netherlands

${ }^{\mathrm{k}}$ Department of Sociology, VU University, Amsterdam, The Netherlands

${ }^{1}$ Department Psychiatry and EMGO Institute for Health and Care Research VU University Medical Center, GGZinGeest, Amsterdam, The Netherlands

${ }^{\mathrm{m}}$ Institute of Neuroscience and Physiology, Neuropsychiatric Epidemiology Unit, Sahlgrenska Academy, Sahlgrenska University Hospital, Sweden

${ }^{\mathrm{n}}$ Institute of Neuroscience and Physiology, Sahlgrenska Academy, University of Gothenburg, Sweden

${ }^{\circ}$ School of Nursing and Human Sciences, Dublin City University, Dublin, Ireland

${ }^{\mathrm{p}}$ General Practice and Primary Care, Institute of Health and Wellbeing, University of Glasgow, UK

${ }^{\mathrm{q}}$ Department of Neurology and Alzheimer Center, Neuroscience Campus, VU University Medical Center, Amsterdam, The Netherlands

${ }^{*}$ Correspondence to: Stephanie J.B. Vos, PhD, Alzheimer Center Limburg, Department of Psychiatry and Neuropsychology, School for Mental Health and Neuroscience, Maastricht Uni- versity, PO Box 616, 6200 MD Maastricht, The Netherlands. Tel.: +31 4338 81036; Fax: +31 4338 84092; E-mail: s.vos@maastrichtuniversity.nl. 


\begin{abstract}
.
Background: Recently, the LIfestyle for BRAin health (LIBRA) index was developed to assess an individual's prevention potential for dementia.

Objective: We investigated the predictive validity of the LIBRA index for incident dementia in midlife, late life, and the oldest-old.

Methods: 9,387 non-demented individuals were recruited from the European population-based DESCRIPA study. An individual's LIBRA index was calculated solely based on modifiable risk factors: depression, diabetes, physical activity, hypertension, obesity, smoking, hypercholesterolemia, coronary heart disease, and mild/moderate alcohol use. Cox regression was used to test the predictive validity of LIBRA for dementia at follow-up (mean $7.2 \mathrm{y}$, range 1-16).

Results: In midlife (55-69 y, $\mathrm{n}=3,256)$ and late life (70-79 y, $\mathrm{n}=4,320)$, the risk for dementia increased with higher LIBRA scores. Individuals in the intermediate- and high-risk groups had a higher risk of dementia than those in the low-risk group. In the oldest-old (80-97 y, $\mathrm{n}=1,811$ ), higher LIBRA scores did not increase the risk for dementia.

Conclusion: LIBRA might be a useful tool to identify individuals for primary prevention interventions of dementia in midlife, and maybe in late life, but not in the oldest-old.
\end{abstract}

Keywords: Aging, dementia, modifiable risk factors, prevention

\section{INTRODUCTION}

Dementia is one of the fastest growing health problems worldwide, without any cure available so far for its most common forms including Alzheimer's disease. This urges the need for prevention. For prevention, early identification of individuals at high risk for dementia is of great importance. In particular, a better understanding of the role of modifiable risk factors in predicting dementia is crucial, as these risk factors constitute promising targets for prevention strategies across a wide age spectrum $[1,2]$.

Recently, the LIfestyle for BRAin health (LIBRA) index was developed to assess an individual's room for prevention of dementia in midlife [3]. The index is a dementia risk score that is defined based on empirical evidence from the existing literature and expert consensus. It includes 12 easily assessable and solely modifiable health and lifestyle factors that are all within the reach of interventions (e.g., physical activity and obesity).

Previously defined dementia risk indices are based on single cohort studies rather than the total evidence in the existing literature [4-8] and/or included nonmodifiable risk factors (e.g., sex, APOE genotype) [4-9]. This makes them less generalizable and less suitable for global prevention strategies. Moreover, some indices were defined in a midlife population [4] whereas others were defined in an older population [6]. Previous research has shown that dementia risk factors may act differently throughout the adult life span $[10,11]$. Thus, more knowledge is needed on the validity of modifiable risk factors in midlife, late life, and the oldest-old to introduce timely and appropriate prevention strategies.
The aim of our study was to test the ability of the LIBRA index to assess the prevention potential by investigating the predictive validity of the LIBRA index for incident dementia in midlife, late life, and the oldest-old in a large multicenter European population-based cohort.

\section{METHODS}

\section{Participants}

Participants were recruited from the DESCRIPA study, a multicenter study consisting of eight harmonized European population-based cohorts. For the current study, six cohorts fulfilled our inclusion criteria: The Swedish Prospective Population Study of Women (GPPSW) [12] and Gerontological and Geriatric Population Study of 85-year-olds (GH85) [13], the Italian Longitudinal Study of Aging (ILSA), [14] the Dutch Longitudinal Aging Study Amsterdam (LASA) [15] and Maastricht Aging Study (MAAS), $[16,17]$ and the French Personnes Agées QUID study (PAQUID). [18] The medical ethics committee at each center approved the study. All subjects provided informed consent.

Inclusion criteria for the current study were age $\geq 55$ years, good subjective general health, a direct or indirect baseline measure of at least 7 out of 9 modifiable risk factors as described below, information on educational level, and at least one clinical follow-up. Individuals with dementia at baseline were excluded.

Clinical assessment was performed according to each study protocol. Generally, it included a medical history by interview or questionnaire, medical and neurological examination, and cognitive assessment. 
For a subgroup, blood sampling was performed. Clinical follow-up assessment was performed at study-specific intervals up to 16 years after baseline. The outcome measure was incident dementia according to the DSM-III-R [19] or for the LASA study defined as impairment in multiple cognitive domains [15].

\section{Risk factors}

Modifiable risk factors were selected from the LIBRA index [3]. We had data available on nine of the 12 risk/protective factors: depression, diabetes, physical inactivity, hypertension, obesity, smoking, hypercholesterolemia, coronary heart disease, and mild/moderate alcohol use. No data were available on cognitive activity, renal dysfunction, and adherence to a Mediterranean diet.

To compose the LIBRA index, direct or indirect measures of the nine risk factors were used according to each study-specific protocol (Supplementary Tables 1 and 2). The LIBRA index was calculated following a previously applied approach based on the relative risk (RR) of all risk factors separately $[4,9]$, as recently reported [3]. Briefly, the natural logarithm (ln) of the RR was calculated for each factor. Next, these were standardized by taking the lowest $\ln (\mathrm{RR})$ as a reference value (score 1) and dividing all other values by this value. Finally, summing the scores of the risk factors resulted in the total LIBRA index. A higher LIBRA score indicates a higher risk for dementia.

Since age, sex, and education are well-established risk factors for dementia, albeit non-modifiable, two extended versions of the LIBRA index were calculated by adding standardized scores of age, sex, and education to the LIBRA index based on the beta weights reported by Anstey and colleagues (age for males, age for females, and years of education; see models 2 and 3 below) [9]. Our educational level categories were slightly different from those used by Anstey and colleagues [9] because the data available in this study were not always coded according to their coding system (Supplementary Table 1). The standardized score for each risk factor is listed in Table 1.

\section{Statistical analyses}

Baseline differences in proportion of risk factors between subjects with and without dementia at follow-up were analyzed using $\chi^{2}$ or Fisher's exact
Table 1

Risk factor scores for incident dementia used to calculate the LIBRA index

\begin{tabular}{|c|c|c|}
\hline & & Risk score \\
\hline \multicolumn{3}{|l|}{ Demographic factors } \\
\hline \multirow[t]{7}{*}{ Age for males } & $<65$ years & 0 \\
\hline & $65-69$ years & 0.4 \\
\hline & $70-74$ years & 5.2 \\
\hline & $75-79$ years & 6.8 \\
\hline & $80-84$ years & 11.2 \\
\hline & $85-89$ years & 14.1 \\
\hline & $\geq 90$ years & 16.4 \\
\hline \multirow[t]{7}{*}{ Age for females } & $<65$ years & 0 \\
\hline & $65-69$ years & 2.1 \\
\hline & $70-74$ years & 6.2 \\
\hline & $75-79$ years & 9.2 \\
\hline & $80-84$ years & 12.4 \\
\hline & $85-89$ years & 15.3 \\
\hline & $\geq 90$ years & 17.6 \\
\hline \multirow[t]{3}{*}{ Educational level } & High & 0 \\
\hline & Medium & 1.4 \\
\hline & Low & 2.7 \\
\hline \multicolumn{3}{|l|}{ Risk factors of LIBRA index } \\
\hline \multirow[t]{2}{*}{ Depression } & No & 0 \\
\hline & Yes & 2.1 \\
\hline \multirow[t]{2}{*}{ Hypertension } & No & 0 \\
\hline & Yes & 1.6 \\
\hline \multirow[t]{2}{*}{ Obesity } & No & 0 \\
\hline & Yes & 1.6 \\
\hline \multirow[t]{2}{*}{ Smoking } & No & 0 \\
\hline & Yes & 1.5 \\
\hline \multirow[t]{2}{*}{ Hypercholesterolemia } & No & 0 \\
\hline & Yes & 1.4 \\
\hline \multirow[t]{2}{*}{ Diabetes } & No & 0 \\
\hline & Yes & 1.3 \\
\hline \multirow[t]{2}{*}{ Physical inactivity } & No & 0 \\
\hline & Yes & 1.1 \\
\hline \multirow[t]{2}{*}{ Coronary heart disease } & No & 0 \\
\hline & Yes & 1.0 \\
\hline \multirow[t]{2}{*}{ Low/moderate alcohol use } & No & 0 \\
\hline & Yes & -1.0 \\
\hline
\end{tabular}

Risk scores were calculated based on relative risks (for the LIBRA risk factors) ${ }^{3}$ and beta coefficients (for the demographic factors) ${ }^{9}$ in the literature, as described in the Methods. The LIBRA index is the sum of the individual risk scores. LIBRA, LIfestyle for BRAin health.

tests. Cox proportional hazards models were used to examine prediction of dementia on a 16-year followup using the LIBRA index (model 1). We performed analyses separately by age groups. Due to the increase in life expectancy and in the mean age of retirement, midlife was defined age 55-69 years, late life age 70-79 years, and oldest-old age 80-97 years. First, analyses were performed for the continuous LIBRA index and C-statistics were calculated as a measure of predictive accuracy. Next, the LIBRA index was categorized into three age-specific risk groups based on tertiles (i.e., low-, intermediate-, high-risk). Additionally, the prediction of dementia by two alternate 
versions of the LIBRA index was tested: LIBRA + educational level (model 2); and LIBRA + age, sex and educational level (model 3). Survival curves of all Cox proportional hazards models were plotted. All analyses were corrected for center. Statistical analyses were done with the SPSS version 23.0 (Chicago, IL, USA) and R Survival package, function SurvConcordance, with significance set at $p<0.05$.

\section{RESULTS}

\section{Sample characteristics}

9,387 participants were included with a mean age of 72.9 (SD 7.3, 55-97) years, of whom 5141 (55\%) were female. $31 \%$ of the cases had data on APOE genotype available. The average LIBRA index was 2.9 (SD 2.0, range -1.0 to 10.5). After an average follow-up of 7.2 years (SD 3.6, range 1 to 16), $1120(12 \%)$ individuals progressed to dementia. The dementia incidence rate was 16.8 (95\% CI 16.0-17.6) per 1000 person-years. The availability and prevalence of risk factors is presented by outcome for each age group separately in Table 2. The availability of risk factors in the total cohort is presented in Supplementary Table 3 . Overall, APOE genotype ( $\varepsilon 4$ carrier versus non-carrier) did not influence predictive accuracy of the LIBRA index for progression to dementia (model 1; LIBRA*APOE HR $=0.97, p=0.664$ ).

\section{Modifiable risk factor profiles for dementia}

\section{Midlife, age 55-69 years}

3,256 individuals were classified in the midlife group (mean age 65.0 (SD 4.0) years; $51 \%$ female), of whom $190(6 \%)$ progressed to dementia after an average follow-up of 8.1 (SD 3.5) years. The dementia incidence rate was 7.2 (95\% CI 6.3-8.1) per 1000 person-years. The average LIBRA index for individuals in midlife was 2.6 (SD 2.1, range -1.0 to 10.5$)$. The risk for dementia increased on a log-linear scale with higher LIBRA scores $(\mathrm{HR}=1.10,1.02-1.18, p=0.020 ; \mathrm{C}$ statistic $0.57, \mathrm{SE}$ 0.03 ; model 1). When educational level (model 2) or age, sex, and educational level (model 3 ) were added to the LIBRA index, the risk for dementia slightly increased $(\mathrm{HR}=1.13,1.06-1.21, p<0.001$ and $\mathrm{HR}=1.11,1.04-1.17, p=0.001$ respectively).

Next, individuals were classified based on tertiles in low $(\mathrm{n}=1070$, score -1.0 to 1.5$)$, intermediate $(n=1132$, score 1.6 to 3.5$)$, and high $(n=1054$, score 3.6 to 10.5 ) dementia risk groups. Table 3 describes the proportions of risk factors in the three risk groups. Individuals in the intermediate- and highrisk groups showed a higher risk for dementia than those in the low-risk group (intermediate $\mathrm{HR}=1.56$, 1.04-2.36, $p=0.033$; high $\mathrm{HR}=1.92,1.25-2.96$, $p=0.003$; Table 4; Fig. 1 ). When education (model 2 ) or age, sex, and education (model 3 ) were added to the LIBRA index results remained similar (Table 4), except that now the increased risk for dementia in the intermediate risk group compared to the low-risk group did not reach statistical significance in model 2 (HR $=1.40,0.96-2.03, p=0.078)$. The high-risk group had an increased dementia risk compared to the intermediate risk group in model $3(\mathrm{HR}=1.44$, $1.04-1.99, p=0.029$ ).

\section{Late life, age 70-79 years}

4,320 individuals were classified in the late life group (mean age 74.5 (SD 2.9) years; $56 \%$ female), of whom $580(13 \%)$ progressed to dementia after an average follow-up of 7.3 (SD 3.5) years. The dementia incidence rate was 18.8 (95\% CI 17.6-20.0) per 1000 person-years. The average LIBRA index for individuals in late life was 3.2 (SD 2.0, range -1.0 to 9.6). The risk for dementia increased on a loglinear scale with higher LIBRA scores $(\mathrm{HR}=1.08$, $1.03-1.13, \mathrm{p}=0.002$; C statistic 0.50 , SE 0.01 ; model 1). The predictive accuracy for dementia slightly increased when educational level (model 2) or age, sex, and educational level (model 3) were added to the index $(\mathrm{HR}=1.10,1.06-1.15, p<0.001$ and $\mathrm{HR}=1.14,1.10-1.17, p<0.001$, respectively).

Individuals in the intermediate $(n=1,496$, score 2.4 to 4.1$)$ and high $(\mathrm{n}=1,392$, score 4.2 to 9.6$)$ risk groups presented a greater risk of incident dementia than those in the low $(n=1,432$, score -1.0 to 2.3 ) risk group (Intermediate $\mathrm{HR}=1.25$, $1.02-1.52, p=0.030$; High $\mathrm{HR}=1.38,1.11-1.72$, $p=0.005$; Table 4; Fig. 1). When education (model 2) or age, sex, and education (model 3 ) were added to the LIBRA index, results remained similar (Table 4), except that the high-risk group had an increased risk for dementia compared to the intermediate risk group in model $3(\mathrm{HR}=2.12,1.73-2.61, p<0.001)$.

\section{Oldest-old, age 80-97 years}

1,811 individuals were classified in the oldest-old group (mean age 83.2 (SD 2.5) years; $58 \%$ female), of whom $350(19 \%)$ progressed to dementia after an average follow-up of 5.5 (SD 3.2) years. The dementia incidence rate was 36.4 (95\% CI 34.1-38.7) per 1000 person-years. The average LIBRA index for 


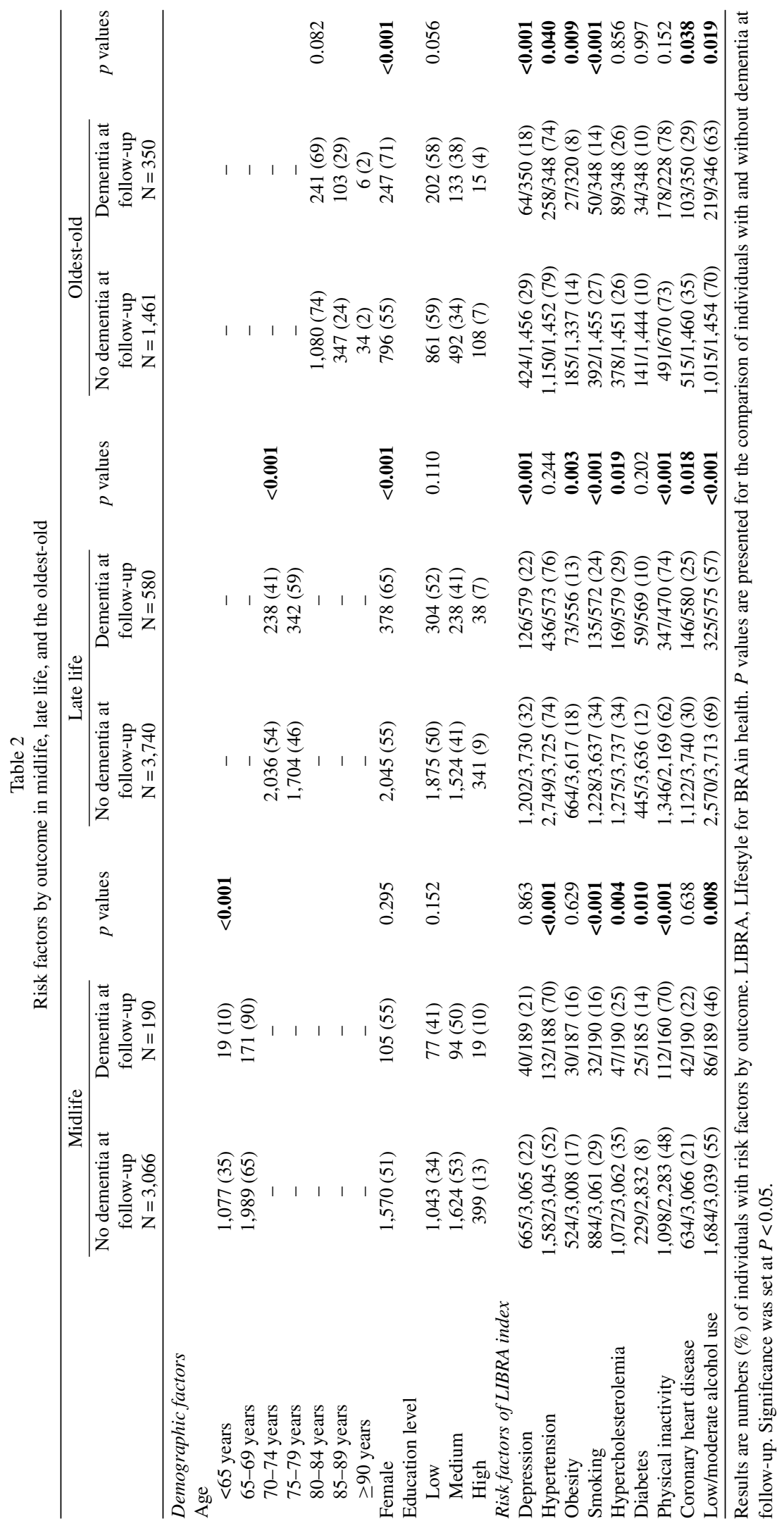




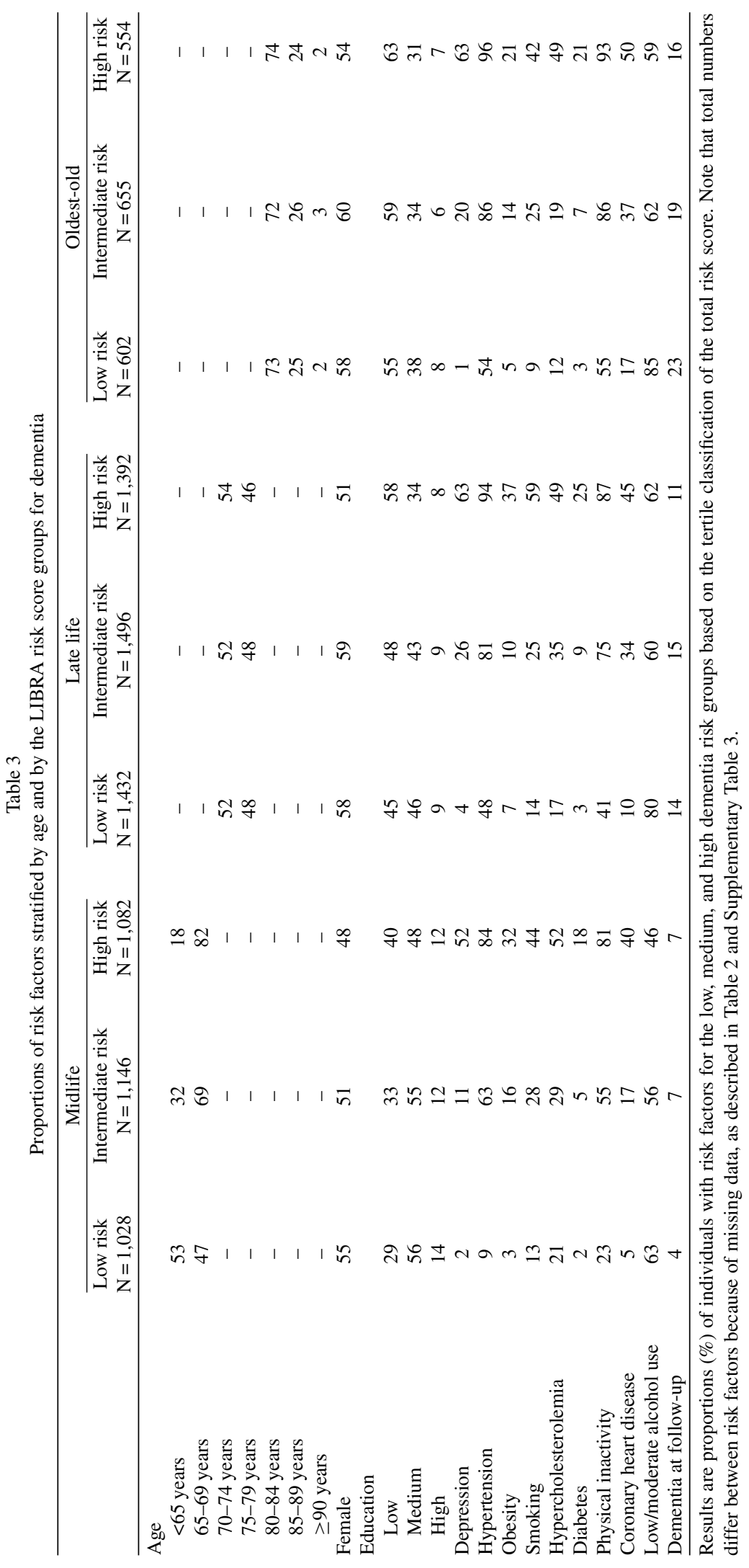




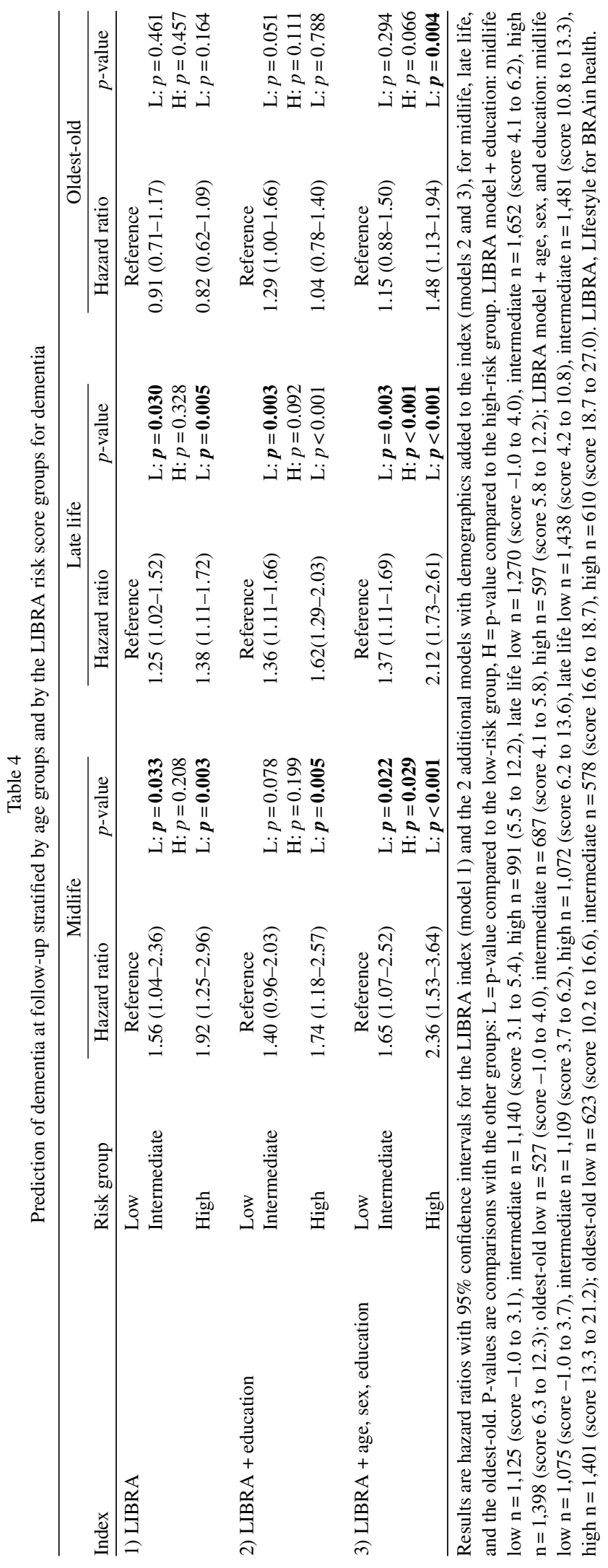


Midlife

\section{(1) LIBRA index}

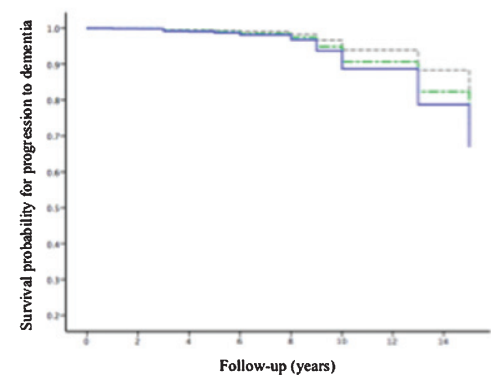

(2) LIBRA index + education

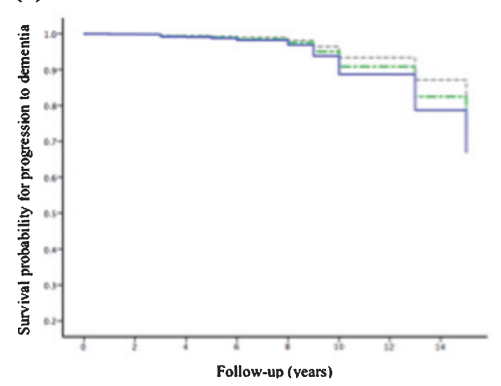

(3) LIBRA index + age, sex, education

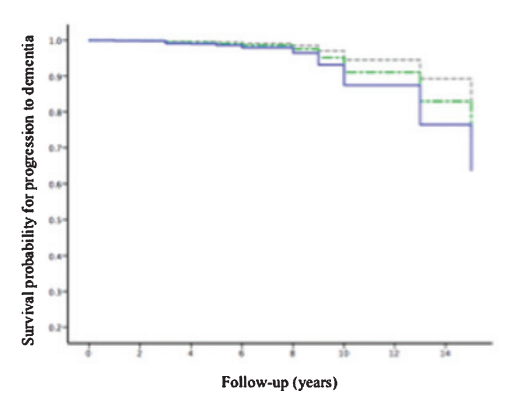

Late life
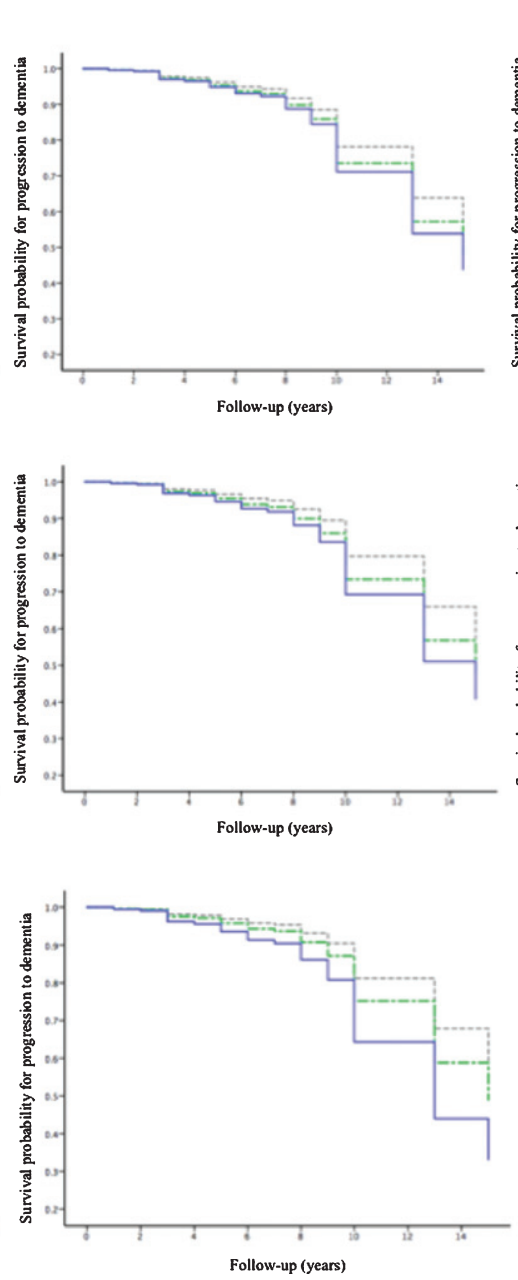

Oldest-old
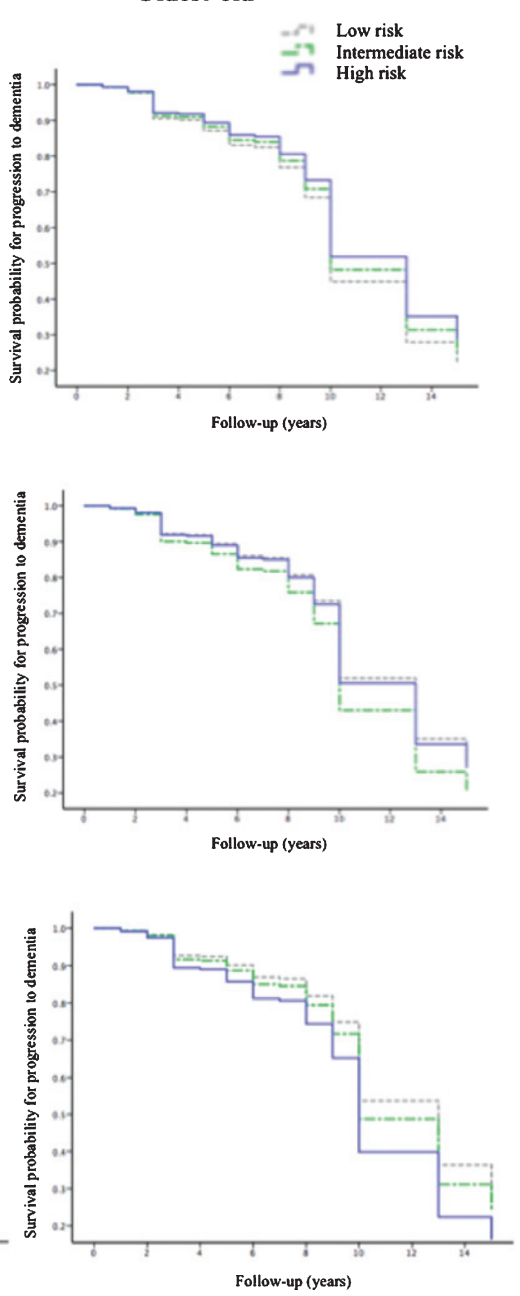

Fig. 1. Survival curves for the LIBRA risk groups. Individuals are classified in risk groups based on tertiles of the LIBRA index score. On the left are survival curves for individuals in midlife, in the middle for individuals in late life, and on the right for the oldest-old. (1) Model 1: Model with the LIBRA index, (2) Model 2: extended model with the LIBRA index + education, and (3) Model 3: extended model with the LIBRA index + age, sex, and education. The dotted grey line represents individuals in the low-risk group, the dotted green line represents individuals in the intermediate-risk group, and the solid blue line represents individuals in the high-risk group.

the oldest-old was 2.9 (SD 1.8, range -1.0 to 9.5 ). The risk for dementia decreased on a log-linear scale with higher LIBRA scores (HR $=0.93,0.88-0.99$, $p=0.031$; C statistic 0.54 , SE 0.02 ; model 1 ). No decreased risk for dementia was found when educational level (model 2) was added to the index (HR $=1.00,0.94-1.05, p=0.870)$. When age, sex, and educational level (model 3 ) were added to the index, the risk for dementia increased with higher LIBRA scores (HR $=1.08,1.13-1.17, p<0.001)$.

Individuals in the intermediate $(\mathrm{n}=655$, score 2.1 to 3.7$)$ and high ( $\mathrm{n}=554$, score 3.8 to 9.5$)$ risk groups did not present greater risk of incident dementia compared to those in the low $(n=602$, score
-1.0 to 2.0 ) risk group (Intermediate $\mathrm{HR}=0.91$, $0.71-1.17, p=0.461$; High $\mathrm{HR}=0.82,0.62-1.09$, $p=0.164$; Table 4; Fig. 1). When education (model 2 ) or age, sex, and education (model 3) were added to the LIBRA index, results were similar (Table 4) but the high-risk group had an increased risk for dementia compared to the low-risk group in model $3(\mathrm{HR}=1.48,1.13-1.94, p=0.004)$.

\section{Modified LIBRA index}

As obesity and hypertension are considered to be major risk factors for later development of dementia only in midlife, we performed an additional analysis 
based on model 1 but with exclusion of obesity and hypertension from the LIBRA index for late life and the oldest-old. In late life, higher modified LIBRA scores were associated with an increased risk for dementia ( $\mathrm{HR}=1.11,1.05-1.17, p<0.001)$. After classifying individuals in risk groups based on tertiles of the modified LIBRA index, we found that the intermediate- and high-risk groups had an increased risk for dementia compared to the low-risk group in late life (intermediate $\mathrm{HR}=1.41,1.16-1.72$, $p=0.001$; high HR $=1.47,1.16-1.86, p=0.002)$. In the oldest-old, the risk for dementia did not increase with higher modified LIBRA scores ( $H R=0.95$, $0.89-1.02, p=0.179)$. The intermediate- and highrisk groups did not have a higher risk for dementia than the low-risk group in the oldest-old (intermediate $\mathrm{HR}=0.97,0.75-1.25, p=0.801$; high $\mathrm{HR}=0.87$, $0.65-1.15, p=0.310)$.

\section{DISCUSSION}

Our study showed that modifiable risk factors based on the LIBRA index could be used to quantify dementia risk in midlife and late life, but not in the oldest-old. Our findings highlight the need for individuals to attain a low LIBRA score, e.g., by adapting a brain-healthy lifestyle and prevention of chronic disease, in order to reduce their risk for dementia.

Alzheimer's disease is the most common form of dementia. Recent evidence suggests that one in three up to one in two Alzheimer's disease cases are potentially attributable to modifiable risk factors. Particularly improved prevention of vascular and metabolic morbidity and depression, and higher levels of education could help to reduce the dementia prevalence worldwide $[1,20]$. Our results indicate that the LIBRA index might be a useful tool to identify individuals for primary prevention interventions of dementia and monitor individuals risk-change over time. Moreover, all LIBRA factors can be easily assessed based on interview and routine medical assessment, which makes it feasible and easily applicable, e.g., in daily primary care practice [21]. Also, other risk factors can be added to the LIBRA index to improve its predictive ability as new evidence becomes available.

Our multicenter data support previous findings that modifiable risk factors may act differently in midlife and later life and that this affects the prediction of dementia. The LIBRA index was specifically designed to determine an individual's room for prevention in midlife. We found that the current index is indeed mainly useful to predict dementia in midlife, and in late life particularly in its modified form, but not in the oldest-old. This corroborates previous reports showing variability in the effects of certain risk factors over the life-course, with some factors having maximum penetrance in midlife rather than in later life, including obesity and hypertension [11,22]. Moreover, most inconsistent findings on predictive ability of risk factors come from late life studies, probably reflecting multi-comorbidity at the oldest age $[10,11,23]$. Our results show that excluding obesity and hypertension from the LIBRA index would not improve quantifying an individual's prevention potential in the oldest-old. However, we found that adding age, sex, and educational level to the LIBRA index in the oldest-old allowed a better differentiation between individuals with lower and higher risk for dementia, whereas this influence was much lower in midlife and early late life. This could partly be explained by the larger weight that was ascribed to older age but also suggests that demographic factors play a lesser role in midlife over and above modifiable factors. Lifestyle-related risk factors may also be affected by brain aging and ongoing cognitive decline, and therefore play a more important role in midlife and early late life. In addition, at the oldest age, underlying dementia-related pathology might have already accumulated so that the predictive value of risk factors becomes lower. The oldest-old might represent a selected group who have survived into old age because of (unknown) resilience factors that compensate for lifelong exposure to poor health and lifestyle.

The LIBRA index is unique in that it reflects an individual's prevention potential for dementia. The predictive accuracy of the LIBRA index for dementia was somewhat lower compared to that of other prediction indices [24]. This is not unexpected given that previous indices were maximized for risk prediction by including major predictors for dementia such as age, gender, education, and APOE genotype. It seems that most of the variance explained by these indices stem from the inclusion of such deterministic factors that are not amenable to change. Furthermore, previous indices were often developed based on a single cohort, and several lack validation in external datasets, increasing the likelihood of overestimating its predictive accuracy [24].

The strengths of our study included the large sample size, relatively long-term follow-up, and generalizability to a wide age spectrum. The use of a multicenter design allowed for a large sample 
size and for testing of age-dependent effects. However, our study had several limitations. Indirect and center-specific measures of risk factors could have introduced heterogeneity in exposure classification. Furthermore, we used only nine out of twelve risk factors of the LIBRA index. The lack of three LIBRA factors (i.e., cognitive activity, renal dysfunction, and adherence to a Mediterranean diet) may have influenced the predictive validity of the LIBRA index. Also, not all individuals had data available for all nine risk factors but when we compared our findings to those for participants with all risk factors available, results remained similar (data not shown). Next, like other indices, LIBRA results in a simple additive score and interactions between risk factors were not taken into account, as this information is not available in the existing literature. Moreover, we used all-cause dementia as outcome measure, given the lack of information on type of dementia. Although Alzheimer's disease was likely the most common diagnosis, investigating the association between risk factors and specific subtypes of dementia would be relevant in future studies. Although our study had a relatively long follow-up (mean 7.2 years, range 1-16) some individuals likely would have progressed to dementia at a later stage, which could increase the predictive validity of the LIBRA index. We did not correct for mortality. Probably, people with higher LIBRA scores present with more multi-morbidity and were more likely to die as a competing risk for dementia. From this perspective, our results might underestimate the true potential of the LIBRA index. Finally, some individuals were already under treatment for a certain risk factor, which may limit the room for prevention.

In sum, our results support the role of modifiable risk factors in the development of dementia and demonstrate the utility and validity of the LIBRA index in midlife and late life up to 79 years. LIBRA can be a useful tool for raising people's awareness and for the identification of individuals who might benefit most from primary prevention strategies through lifestyle change or health management. Further validation of the LIBRA index is needed in external datasets and subgroups such as individuals with mild cognitive impairment.

\section{ACKNOWLEDGMENTS}

This research was supported by the European Union Fifth Framework Programme under grant agreement No. QLRT-2001-2455 (DESCRIPA),
European Union Seventh Framework Programme (FP7/2007-2013) under grant agreement No. 304979 (In-MINDD), and EU/EFPIA Innovative Medicines Initiative Joint Undertaking under European Medical Information Framework grant agreement No. 115372 (EMIF-AD).

Authors' disclosures available online (http:// j-alz.com/manuscript-disclosures/16-1208r2).

\section{SUPPLEMENTARY MATERIAL}

The supplementary material is available in the electronic version of this article: http://dx.doi.org/ 10.3233/JAD-161208.

\section{REFERENCES}

[1] Norton S, Matthews FE, Barnes DE, Yaffe K, Brayne C (2014) Potential for primary prevention of Alzheimer's disease: An analysis of population-based data. Lancet Neurol 13, 788-794.

[2] Di Marco LY, Marzo A, Munoz-Ruiz M, Ikram MA, Kivipelto M, Ruefenacht D, Venneri A, Soininen H, Wanke I, Ventikos YA, Frangi AF (2014) Modifiable lifestyle factors in dementia: A systematic review of longitudinal observational cohort studies. J Alzheimers Dis 42, 119-135.

[3] Deckers K, van Boxtel MP, Schiepers OJ, de Vugt M, Muñoz Sánchez JL, Anstey KJ, Brayne C, Dartigues JF, Engedal K, Kivipelto M, Ritchie K, Starr JM, Yaffe K, Irving K, Verhey FR, Köhler S (2015) Target risk factors for dementia prevention: A systematic review and Delphi consensus study on the evidence from observational studies. Int J Geriatr Psychiatry 30, 234-146.

[4] Kivipelto M, Ngandu T, Laatikainen T, Winblad B, Soininen H, Tuomilehto J (2006) Risk score for the prediction of dementia risk in 20 years among middle aged people: A longitudinal, population-based study. Lancet Neurol 5, 735-741.

[5] Barnes DE, Covinsky KE, Whitmer RA, Kuller LH, Lopez OL, Yaffe K (2009) Predicting risk of dementia in older adults: The late-life dementia risk index. Neurology 73, 173-179.

[6] Reitz C, Tang MX, Schupf N, Manly JJ, Mayeux R, Luchsinger JA (2010) A summary risk score for the prediction of Alzheimer disease in elderly persons. Arch Neurol 67, 835-841.

[7] Jessen F, Wiese B, Bickel H, Eiffländer-Forfer S, Fuchs A, Kaduszkiewicz H, Köhler M, Luck T, Mösch E, Pentzek M, Riedel-Heller SG, Wagner M, Weyerer S, Maier W, van den Bussche H; AgeCoDe Study Group (2011) Prediction of dementia in primary care patients. PLoS One 6, e16852.

[8] Exalto LG, Quesenberry CP, Barnes D, Kivipelto M, Biessels GJ, Whitmer RA (2014) Midlife risk score for the prediction of dementia four decades later. Alzheimers Dement 10, 562-570.

[9] Anstey KJ, Cherbuin N, Herath PM (2013) Development of a new method for assessing global risk of Alzheimer's disease for use in population health approaches to prevention. Prev Sci 14, 411-421. 
[10] Anstey KJ, Lipnicki DM, Low LF (2008) Cholesterol as a risk factor for dementia and cognitive decline: A systematic review of prospective studies with meta-analysis. Am J Geriat Psychiat 16, 343-354.

[11] Anstey KJ, Cherbuin N, Budge M, Young J (2011) Body mass index in midlife and late-life as a risk factor for dementia: A meta-analysis of prospective studies. Obes Rev 12, e426-437.

[12] Guo X, Waern M, Sjogren K, Lissner L, Bengtsson C, Björkelund C, Ostling S, Gustafson D, Skoog I (2007) Midlife respiratory function and Incidence of Alzheimer's disease: A 29-year longitudinal study in women. Neurobiol Aging 28, 343-350.

[13] Skoog I, Nilsson L, Palmertz B, Andreasson LA, Svanborg A (1993) A population-based study of dementia in 85-yearolds. $N$ Engl J Med 328, 153-158.

[14] Maggi S, Zucchetto M, Grigoletto F, Baldereschi M, Candelise L, Scarpini E, Scarlato G, Amaducci L (1994) The Italian Longitudinal Study on Aging (ILSA): Design and methods. Aging 6, 464-473.

[15] Huisman M, Poppelaars J, van der Horst M, Beekman AT, Brug J, van Tilburg TG, Deeg DJ (2011) Cohort profile: The Longitudinal Aging Study Amsterdam. Int J Epidemiol 40, 868-876.

[16] van Boxtel MP, Buntinx F, Houx PJ, Metsemakers JF, Knottnerus A, Jolles J (1998) The relation between morbidity and cognitive performance in a normal aging population. J Gerontol A Biol Sci Med Sci 53, M147-154.

[17] Jolles J, Houx PJ, van Boxtel MPJ, Ponds RWHM (1995) Maastricht Aging Study: Determinants of cognitive aging. Neuropsych Publishers, Maastricht.
[18] Dartigues JF, Gagnon M, Barberger-Gateau P, Letenneur L, Commenges D, Sauvel C, Michel P, Salamon R (1992) The Paquid epidemiological program on brain ageing. Neuroepidemiology 11, 14-18.

[19] American Psychiatric Association (1987) Diagnostic and statistical manual of mental disorders, 3rd revised. American Psychiatric Association, Washington, DC.

[20] Matthews FE, Arthur A, Barnes LE, Bond J, Jagger C, Robinson L, Brayne C, on behalf of the Medical Research Council Cognitive Function and Ageing Collaboration (2013) A two-decade comparison of prevalence of dementia in individuals aged 65 years and older from three geographical areas of England: Results of the Cognitive Function and Ageing Study I and II. Lancet 382, 1405-1412.

[21] O’Donnell CA, Manera V, Kohler S, Irving K (2015) Promoting modifiable risk factors for dementia: Is there a role for general practice? Br J Gen Pract 65, 567-568.

[22] Fratiglioni L, Qiu C (2011) Prevention of cognitive decline in ageing: Dementia as the target, delayed onset as the goal. Lancet Neurol 10, 778-779.

[23] Power MC, Weuve J, Gagne JJ, McQueen MB, Viswanathan A, Blacker D (2011) The Association between blood pressure and incident Alzheimer disease a systematic review and meta-analysis. Epidemiology 22, 646-659.

[24] Tang EY, Harrison SL, Errington L, Gordon MF, Visser PJ, Novak G, Dufouil C, Brayne C, Robinson L, Launer LJ, Stephan BC (2015) Current developments in dementia risk prediction modelling: An updated systematic review. PLoS One 10, $\mathrm{e} 0136181$. 